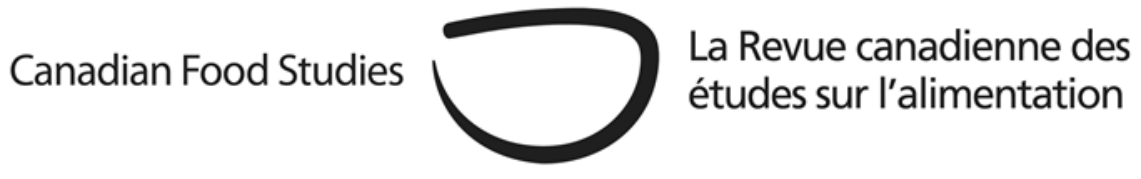

Perspective Article

\title{
Student food literacy, critical food systems pedagogy, and the responsibility of postsecondary institutions
}

Michael Classens* and Emily Sytsma

Trent University

\begin{abstract}
There has recently been a marked increase in scholarly interest in both food systems pedagogy and food literacy. So far, however, there has been very little work attending to the intersection of these two crucially important interventions. We argue that a distinctly critical food systems pedagogy must be grounded in and enabled through an equally critical food literacy. We forward a provisional definition of critical food literacy and make the argument that postsecondary institutions should be invested in ensuring that all students - not only food studies students - are exposed to critical food literacy training.
\end{abstract}

Keywords: Critical food systems education; student food literacy; post-secondary learning; food systems

*Corresponding author: michaelclassens@trentu.ca 


\section{Introduction}

Up until very recently, and with very few exceptions, food systems pedagogy has not had much attention from scholars. As one of a small handful of leaders in the field puts it, "those who study learning have not often turned their gaze toward food, while those who study food have generally overlooked the learning associated with it" (Sumner, 2016, p. xix). However, this is beginning to change. Scholars are sketching the contours of a food systems pedagogy — an approach to teaching and learning about food that is interdisciplinary (Valley et al., 2017), that embraces complexity (Jordan et al., 2014), and that includes experiential learning opportunities (Levkoe et al., 2018; Miller et al., 2012). Importantly, scholars are insisting that critical food systems pedagogy must also be values-based (Galt et al., 2012, p. 43) and pose a challenge to the social and ecological injustice perpetuated by the contemporary industrial food system (Flowers \& Swan, 2012; Sumner, 2016).

This is all crucial work, but where does food literacy fit in? Though it remains "a concept under construction" (Sumner, 2013, p. 82), we argue that food literacy must be incorporated into and supported by critical food systems pedagogy in order for the field to be truly transformative. This union ought to be the foundation of existing food studies programs - but, perhaps more importantly, we also argue that critical food literacy ought to be a university-wide commitment meant to benefit all students, not only those enrolled in food studies programs. Taking the "pedagogical turn" (Flowers \& Swan, 2012, p. 424) in food studies seriously requires a commitment to food learning beyond the immediate walls of the food studies classroom. It means asking, "how do we help citizens, not consumers, engage positively with their food system?" (Slater, 2017, p. 18). All students eat—-though far too many face food insecurity-so we argue that postsecondary institutions need to take some ownership over educating their students in critical food literacy. Jennifer Sumner (2013) suggests that critical food literacy allows us to "read the world through food" (p. 86). Our focus within this short piece is narrower, but our proposition is no less provocative: how might we transform our campuses by reading them through food?

\section{Food literacy}

Consensus has yet to emerge on the meaning of food literacy (see Truman et al., 2017; Velardo, 2015), and indeed a range of diverse meanings may be central to the ongoing value of the term within food-learning contexts. ${ }^{1}$ Truman et al. (2017) recently proposed a useful working definition of food literacy, informed by a comprehensive scan of related literature and engagement with key stakeholders. Their work reveals two interrelated categories of knowledge related to food literacy. Functional knowledge includes "broad sets of skills and

\footnotetext{
${ }^{1}$ A recent scoping review by Truman et al. (2017) found thirty-nine distinct definitions of food literacy.
} 
knowledge...food identification; physical, emotional and mental effects of food; as well as basic abilities related to food" (Truman et al., 2017, p. 213). Critical knowledge, on the other hand, "allows people to perform actions related to food and think critically about their relationship to the broader food system" (Truman et al., 2017, p. 213). Drawing on notions of critical literacy, Yamashita and Robinson (2016) propose four elements of distinctly critical food systems literacy, including the ability to "(1) examine one's own values with respect to food systems; (2) grapple with multiple values and perspectives that underlie food systems; (3) understand the larger sociopolitical contexts and factors that shape food systems; and (4) take action toward social justice in food systems and sustainability more broadly" (p. 273).

Our own provisional understanding of food literacy attempts to integrate the practical with the political, recognizing that our everyday encounters with food are both pedestrian and profound and that food literacy should equip us to deal with food in this way. We thus interpret critical food literacy in broad terms, as a set of skills, knowledge, and understandings that (1) equip individuals to plan, manage, prepare, and eat food that is healthy, culturally appropriate, and sustainable, while (2) enabling them to understand the broader sociopolitical and ecological dynamics of the food system, and (3) empowering them to incite socioecological change within the food system.

The work of conceptualizing how to weave critical food literacy into the fabric of campus life is an ambitious project, beyond the scope of this short text. Instead, to illustrate the analytic power and transformative potential of critical food literacy, we briefly consider student food (in)security on campus in a number of cases. Despite the fact that food literacy skills have been shown to play a key role in a variety of important areas related to health outcomes and food security (Anderson, 2007; Thomas \& Irwin, 2011), reducing food insecurity to a simple matter of food literacy is highly problematic (Huisken et al., 2017). That is not our intention here. However, the incidence of food insecurity among university students is very high (Maynard et al., 2018a; Nazim et al., 2019), not particularly well understood (Bruening et al. 2017), and, as we discuss immediately below, may be undermining the educational mandate of universities (Farahbakhsh et al., 2017). We therefore suggest that every tool available should be deployed to better understand and end student food insecurity, and we argue that critical food literacy can contribute productively to this end.

\section{Student food insecurity}

The scope and depth of postsecondary student food insecurity is not well understood (Bruening et al., 2017), however, available research suggests it is an alarming and growing problem (Maynard et al., 2018a; Nazim et al., 2019). Those who are food insecure have limited access to the adequate and appropriate food required to meet their nutritional needs and struggle to acquire food in a "socially acceptable way" (Olauson et al., 2018). At Trent University (our own 
institution), nearly half of all first-year students recently reported being food insecure (Dasné \& Furgal, 2017). This is nearly triple the rate of food insecurity in our wider municipal community of Peterborough, which, at sixteen percent, is among the highest in the province (Peterborough Public Health, 2018). Nationally, forty percent of students will experience food insecurity at some point during their postsecondary career (Maynard et al., 2018a). A two-decade trend of rising tuition fees and cost of living, coupled with a stagnating value of student grants, seems to be exacerbating campus food insecurity (Farahbakhsh et al., 2015; Farahbakhsh et al., 2017). Meanwhile, a persistent 'starving student' ideology normalizes the conditions that leave so many students food insecure (Maynard et al., 2018b).

There is scarce research on the long-term effects of food insecurity on postsecondary students, though adjacent data are instructive. Food insecurity among adolescents has been shown to elevate stress and anxiety, resulting in poorer education outcomes (Jyoti et al., 2005). In adults, meanwhile, food insecurity leads to chronic health problems (Laraia, 2013; Seligman et al., 2010) and lower work productivity (Borre et al., 2010; Devine et al., 2006). In a recent study conducted with users of the campus food bank at the University of Alberta, researchers found that students who identified as severely food insecure had more difficulty concentrating during class, attending class, studying for exams, and completing assignments than their more food secure counterparts (Farahbakhsh et al., 2017). Importantly, factors such as academic achievement and wellness contribute to student retention and graduation rates (Cady, 2014). Postsecondary institutions have taken notice, as demonstrated by the proliferation of on-campus food banks in recent years (Farahbakhsh et al., 2017). Yet this is a wholly insufficient intervention. By undermining successful learning outcomes, and potentially creating an impact on student retention and graduation rates, student food insecurity threatens the raison d'etre of postsecondary institutions. For this reason alone, food security — and critical food literacyought to be central commitments on all campuses.

The limitations of the current status quo, as we see them, are threefold. First, many campuses outsource their food services to internationally owned institutional providers, such as Chartwells or Aramark. These institutional providers rely on large contracts with food suppliers to ensure a consistent supply while maximizing their profit margins. This tends to result in an emphasis on processed foods to avoid the high-labour costs associated with cooking with fresh ingredients (Reynolds \& Hunter, 2017). Students beholden to these corporate food services are taking note of the implications. In a survey conducted by the Canadian Federation of StudentsOntario (2017), students highlighted a lack of variety as a key concern. This is especially relevant for international students, who have little access to culturally appropriate foods on campus. The report also showed that the most common critique registered by students was with respect to the high price of food at on-campus retailers relative to off-campus locations. For students on campuses situated outside of urban centres - in veritable food deserts, like those at Trent University - lack of variety and high costs are inescapable realties. At the same time, these procurement strategies, accompanied by stringent food-safety standards, create substantial barriers to the attempts of small-scale local suppliers to gain access to the public food sector 
market and ultimately reinforce the industrial food system (Reynolds \& Hunter, 2017). Yet Stahlbrand (2016) emphasizes the potential for large public institution purchasers to drive local procurement and, in turn, improve food system sustainability.

In a related way, students are generally not supported to understand where their campus food comes from, including how it was grown, who grew it (and under what conditions), or who prepared it (and under what conditions). Even where local procurement strategies are implemented by institutions, Maynard et al. (2018b) found that forty-three percent of students were not aware of local sourcing efforts on campus, and seventy-seven percent of students were not familiar with fair-trade programs on campus. This suggests that our postsecondary institutions are failing to communicate even the 'good news' stories about campus food, leaving a vast disconnect between food service and students' perceptions of the food to which they have access on campus. The little information students get about their food from promotional materials and labeling schemes - while often portrayed as an attempt at promoting food literacy and transparency - is of questionable value. Nutritionism, the process by which food is reduced to its nutritional content or its professed disease preventing capabilities, is a key marketing technique used to propel industrial food (Scrinis, 2008). Placing caloric values on menus reduces food to its most basic biological component and ignores not only the source of those calories (e.g., fats, sugars, proteins) but also the journey that food has taken from farm and factory to plate. An emphasis on labels — whether nutritional, fair trade, local, or organic — can also be depoliticizing, recasting students as (ethical) individualized consumers and reinforcing the neoliberal notion that we can shop our way to a better world (Low \& Davenport, 2007).

This is compounded by a second threat to food literacy and security - the lack of oncampus amenities to support student cooking. Many students, particularly those living in residence, have little access to proper facilities for storing and cooking food. At Trent, for example, dorms are not equipped with kitchens. Even for off-campus students who wish to bring their own food, finding a microwave on campus to reheat homemade meals can be a serious challenge. Without a fridge to store fresh groceries, a stovetop to cook a homemade meal, or a microwave to reheat leftovers, students are left with little choice but to frequent the cafeterias, where they will often pay more for individual meals than if they had shopped in the supermarket or farmers' market. The lack of supportive amenities on campus channels students to the fastfood offerings, likely reinforcing the corporate food paradigm and contributing to food deskilling and food illiteracy.

Finally, these two preceding issues are - in our experience - exacerbated by very little critical food literacy curriculum content. Despite an increasingly rich and insightful range of food systems curricula at a handful of universities across Canada (see for example Valley et al., 2017), most students outside of food studies programs are not likely to encounter even an introduction to practical food skills in any of their classes, let alone the more ambitious lessons of critical food literacy. At Trent, students have access to a number of courses that offer critical appraisals of the contemporary food system, including a course called "The Edible Campus" that centres campus food systems as an empirical focus for scrutiny. Nonetheless, these courses reach 
an exceedingly small percentage of Trent students. For example, "The Edible Campus," a small fourth-year course taught by the first author, typically has ten to twelve students per year, a fraction of a percent of the over 10,000 students enrolled at the university. Trent does boast a thriving set of campus entities - for example the Sustainable Agriculture and Food Systems Student Society and The Seasoned Spoon (a non-profit vegetarian café that operates independently of Chartwells) - that organize occasional workshops designed to increase student food literacy. However, they are largely student run, funded through student levy fees, and do not have the capacity to provide a comprehensive, campus-wide approach to critical food literacy.

\section{Toward a comprehensive food pedagogy}

Food literacy begins long before people attend university. We are constantly learning, in informal ways, through our every encounter with food (see Sumner, 2016). Food is discovered, understood, and appreciated through informal learning in the home - whether searching for an online recipe and making an ingredients list or following along as a family member cooks a traditional dish. Informal food learning also continuously happens in our communities. Growing a garden, talking to local farmers at the market, sharing recipes with neighbours, and cooking and eating with friends and family all contribute to food literacy from a young age. And yet, deskilling is a constant spectre and ongoing threat to food literacy and food security (see Desjardins et al., 2013). These skills and knowledge are lost as families struggle for the time, money, and skills required to maintain a diet that not only provides basic nutrient requirements but also adds joy and meaning to life (Slater, 2013). Parents have reported wanting to include children in meal preparation, but this is weighed against a desire to mitigate mess and time wastage (Fulkerson et al., 2011). With young children in the house, the kitchen can become an off-limits space (Slater, 2013), a place of no-nonsense utility, in the nightly scramble of dinnerdishes-bath-bedtime.

By the time they reach adolescence, many young people tend to have low levels of food literacy with respect to practical skills and capabilities, and they have minimal knowledge about the broader socioecological and political aspects of their food systems (Ronto et al., 2016). There are very few opportunities outside the classroom designed to increase food literacy among adolescents (Thomas \& Irwin, 2011). Within the classroom, the opportunities are not much better. The Ontario high school curriculum includes one food and nutrition course for grade nine or ten and one nutrition and health class for each stream (workplace, college and university preparation) in grade twelve (Ontario Ministry of Education, 2019). None of these courses are compulsory - though civil-society actors are actively lobbying the provincial government to change that (see Ontario Home Economics Association, 2018). Adolescents do, of course, learn about food (though not necessarily food systems) in informal settings, however research suggests 
that rates of adolescent food literacy remain low (Ronto et al., 2016). Furthermore, their diets are typified by high consumption of sweetened beverages and fast food (Nelson et al., 2008; Worsley, 2015).

It is therefore not surprising that by the time students arrive at postsecondary institutions they are predisposed to selecting the convenience items available in cafeterias and on-site fast food franchises. And yet, rather than organize the campus food system in ways that enable different choices to be made, most universities - through the three-pronged process described above - reinforce food illiteracy. Nevertheless, many university and college students are at a key developmental stage of figuring out who they are, determining what their core commitments are, and establishing the patterns they will carry with them well beyond their school days (Tam et al., 2016). In other words, this period is a critical intervention opportunity to support students in prefiguring relationships to food that are different from the conventional ones promoted by our campus food systems.

To date, a number of responses have been enacted. For example, some campuses offer cooking classes and food budgeting workshops (Maynard et al., 2018b). On our own campus, The Seasoned Spoon offers a number of workshops for purchasing and cooking food on a tight budget. While these workshops have an impact on those who take them, they reach only a handful of students, and are ultimately of limited utility in the face of the broader issues outlined here. What is required, instead, is a comprehensive and supportive approach to student food literacy. At universities offering food studies or food sciences degrees, food literacy should be integrated into the broader pedagogical approach of the program.

While we resist being overly prescriptive (given the diverse contexts and student populations at postsecondary institutions), it is clear that campuses can be doing more to improve food security and support student food literacy on campus. Campuses need better kitchen and food-preparation facilities both for students in residence and for those who live off-campus. Campuses should remove corporate fast food chains and replace them with independent retailers that source locally produced goods. Canadian campuses have considerable purchasing power and therefore have the capacity to induce change (Reynolds \& Hunter, 2017). Indeed, research suggests that innovative institutional procurement approaches can support social justice and environmental sustainability outcomes (Friedmann, 2007; Stahlbrand, 2016).

All students should receive basic education about food systems, including the social and ecological unsustainability of current practices, as well as specific examples of the inspiring work underway to forge alternatives, both locally and in other regions. All students should be enabled to learn basic budgeting and cooking skills and to reduce their reliance on meal plans. Campuses should host more farmers' markets, encouraging students to engage with growers and acquire a deeper understanding of local food systems. Campus organizations should support cooking demonstrations, while campus newspapers should print healthful and budget-friendly recipes that students can make with their friends and roommates. Administrators should seek out food-service providers that can deliver sustainably produced, culturally appropriate, and healthful food, while supporting students with the knowledge and tools of food literacy. In short, 
postsecondary institutions should take on the challenge of ensuring that all of their students are food secure.

Most of all, students themselves should be consulted, engaged, and encouraged to act. Beyond paying for the campus food system through their tuition and food purchases, their bodies, psyches, and academic and personal successes are beholden to that system. At Trent, we have anecdotal evidence to suggest that administrations are willing to listen. In 2014, the Trent Central Student Association (TCSA, Trent's undergraduate student union) published what amounted to an indictment of Trent's campus food system (TCSA, 2014). They found that ninety-seven percent of student respondents $(n=661)$ were unsatisfied with the food services available on campus. The report included twelve recommendations, from increasing the presence of food vendors not subject to the primary corporate food contract to ensuring that all eating areas on campus are open to all students, not only those with the ability to pay. Encouragingly, and to the credit of Trent Food Services, many of the recommendations in the report have been implemented in the last five years ${ }^{2}$. There is nonetheless much more to be done, particularly around the support for food literacy.

Finally, it is worth underscoring that integrating food literacy and the struggle for student food security into food systems curricula is an important way of enhancing food systems pedagogy. The feminist geographer Gibson-Graham (2006) argues that a good way to start making positive change is to take advantage of "the ubiquitous starting place of here and now" (emphasis original, p. 194). For values-based, justice-oriented food studies programs, the here and now of the campus provides an effective window through which to view the broader problems of our contemporary food systems. For example, teaching food literacy to students on campus also provides an opportunity to teach about the gendered nature of food labour and food deskilling. Investigating where campus food comes from, and why the food choices on campus are the way they are, can introduce other themes, such as the political economy of corporate food systems. Similarly, talking about student food insecurity can help articulate the inequality of food systems in concrete terms. In parallel, collaborating with groups that foster student food literacy and student food security on campus is a way for educators to reveal to their students the important world of food justice advocacy and to teach their students about the power of political organizing and solidarity. In turn, integrating formal learning in classrooms with non-formal learning initiatives hosted by allied groups (e.g., student unions, campus food advocacy groups, local activist organizations) can be a way to enrich the student experience while demonstrating linkages between education, future professional work, and social engagement.

University campuses are an ideal context in which to model many important and progressive practices - from prioritizing equity and diversity to pursuing environmental sustainability. In parallel, campus food systems represent a new horizon for food systems pedagogy to help shape a food-literate and food-secure population. By incorporating occasions to adopt a focus on critical food literacy, food systems curricula can support and even lead this

\footnotetext{
2 There are plans underway to reproduce the 2014 study in the coming academic year.
} 
effort. The result will be widespread student success, as well as food systems students who are better prepared to understand, survive within, and challenge the social and ecological unsustainability of the contemporary corporate food system.

\section{References}

Anderson, A. (2007). Nutrition interventions in women in low-income groups in the UK. Proceedings of the Nutrition Society, 66(1), 25-32. DOI: 10.1017/S0029665107005265

Borre, K., Ertle, L., \& Graff, M. (2010). Working to eat: Vulnerability, food insecurity, and obesity among migrant and seasonal farmworker families. American Journal of Industrial Medicine, 53(4), 443-462. DOI: 10.1002/ajim.20836

Bruening, M., Agro, K., Payne-Sturges, D., \& Laska, MN. (2017). The struggle is real: A systemic review of food insecurity on postsecondary education campuses. Journal of the Academy of Nutrition and Dietetics, 117(11), 1767-1791. DOI: 10.1016/j.jand.2017.05.022

Cady, C. L. (2014). Food insecurity as a student issue. Journal of College and Character, 15(4), 265-272. DOI: 10.1515/jcc-2014-0031

Canadian Federation of Students-Ontario. (2017). Task force on campus food services. http://cfsontario.ca/wp-content/uploads/2017/07/CFS-2013FoodReport.pdf

Dasné, S., \& Furgal, C. (2017). Food security at Trent University: Key results from the 20162017 food access survey. Unpublished report.

Desjardins, E., Davidson, L., Samra, R., MacDonald, A., Dunbar, J., Thomas, H., Munoz, M., King, B., Maxwell, T., Wong-McGraw, P., \& Shukla, R. (2013). Making something out of nothing: Food literacy among youth, young pregnant women and young parents who are at risk for poor health. Locally Driven Collaborative Projects Food Skills Ontario, Technical Report November https://foodsecurecanada.org/sites/foodsecurecanada.org/files/food_literacy_study_technic al_report_web_final.pdf

Devine, C. M., Jastran, M., Jabs, J. A., Wethington, E., Farrell, T. J., \& Bisogni, C. A. (2006). "A lot of sacrifices:" Work-family spillover and the food choice coping strategies of lowwage employed parents. Social Science and Medicine, 63(10), 2591-2603. DOI: 10.1016/j.socscimed.2006.06.029

Farahbakhsh, J., Ball, G., Farmer, A. P., Maximova, K., Hanbazaza, M., \& Willows, N. (2015). How do student clients of a university-based food bank cope with food insecurity? Canadian Journal of Dietetic Practice Research, 76, 200-203. DOI: 10.3148/cjdpr-2015020

Farahbakhsh, J., Hanbazaza, M., Ball, G. D., Farmer, A. P., Maximova, K., \& Willows, N. D. (2017). Food insecure student clients of a university-based food bank have compromised health, dietary intake and academic quality. Nutrition and Dietetics, 74, 67-73. DOI: 10.1111/1747-0080.12307 
Flowers, R., \& Swan, E. (2012). Introduction: Why food? What pedagogy? Why adult education? Australian Journal of Adult Learning, 52(3), 419-433.

Friedmann, H. (2007). Scaling up: Brining public institutions and food service corporations into the project for a local, sustainable food system in Ontario. Agriculture and Human Values, 24, 389-398. DOI: 10.1007/s10460-006-9040-2

Fulkerson, J., Kunick, M. Y., Rydell, S., Boutelle, K. N., Garwick, A., Story, M., NeumarkSztainer, D., \& Dudovitz, B. (2011). Focus groups with working parents of school-aged children: What's needed to improve family meals. Journal of Nutrition Education and Behavior, 43(3), 189-193. DOI: 10.1016/j.jneb.2010.03.006

Galt, R., Clark, S., \& Parr, D. (2012). Engaging values in sustainable agriculture and food systems education: Toward an explicitly values-based pedagogical approach. Journal of Agriculture, Food Systems, and Community Development, 2(3), 43-54. https://foodsystemsjournal.org/index.php/fsj/article/view/108

Gibson-Graham, J. K. (2006). A postcapitalist politics. University of Minnesota Press.

Huisken, A., Orr, S. K., \& Tarasuk, V. (2017). Adults' food skills and use of gardens are not associated with household food insecurity in Canada. Canadian Journal of Public Health, 107(6), e526-e532. DOI: 10.17269/CJPH.107.5692

Jordan, N., Grossman, J., Lawrence, P., Harmon, A., Dyer., W., Maxwell, B., Cadieux, KV., Galt, R., Rojas, A., Byker, C., Ahmed, S., Bass, T., Kebreab, E.. Singh, V., Michaels, T., \& Tzenis, C. (2014). New curricula for undergraduate food-systems education: A sustainable agriculture education perspective. NACTA Journal December, 302-310.

Jyoti, D. F., Frongillo, E. A., \& Jones, S. J. (2005). Food insecurity affects school children's academic performance, weight gain, and social skills. Journal of Nutrition, 135(12), 28312839. DOI: $10.1093 / \mathrm{jn} / 135.12 .2831$

Laraia, B. A. (2013). Food insecurity and chronic disease. Advances in Nutrition, 4(2), 203-212. DOI: $10.3945 /$ jn.109.112573

Levkoe, C. Z., Friendly, A., \& Daniere, A. (2018). Community service-learning in graduate planning education. Journal of Planning Education and Research. DOI: $10.1177 / 0739456 \times 18754318$

Low, W. \& Davenport, E. (2007). To boldly go...exploring ethical spaces to re-politicise ethical consumption and fair trade. Journal of Consumer Behaviour, 6(5), 336-348. DOI: $10.1002 /$ cb. 226

Maynard, M. S., Meyer, S. B., Perlman, C. M., \& Kirkpatrick, S. I. (2018a). Experience of food insecurity among undergraduate students: "You can't starve yourself through school." Canadian Journal of Higher Education, 48(2), 130-148.

Maynard, M., Lahey, D., \& Abraham A. (2018b). Campus food report card: The state of food on Ontario university campuses. Meal Exchange. https://www.mealexchange.com/reportcard/

Miller, S., Lee, J. S., \& Berle, D. (2012). Community engagement from the ground up: An interdisciplinary service-learning after-school garden program. Journal of Agriculture, 
Food Systems, and Community Development, 2(3), 121-135. DOI:

10.5304/jafscd.2012.023.013

Nazim, A., Martinez, S., Byrd, A., Robinson, D., Bianco, S., \& Maguire, J. (2019). A systematic review of food insecurity among US students in higher education. Journal of Hunger and Environmental Nutrition, 14(5), 725-740. DOI: 10.1186/s12889-019-6943-6

Nelson, M., Story, M., Larson, N., Neumark-Sztainer, D., \& Lytle, L. (2008). Emerging adulthood and college-aged youth: An overlooked age for weight related behavior change. Obesity, 16(10), 2205-2211 DOI: 10.1038/oby.2008.365

Olauson, C., Engler-Stringer, R., Vatanparast, H., \& Hanoski, R. (2018). Student food insecurity: Examining barriers to higher education at the University of Saskatchewan. Journal of Hunger and Environmental Nutrition, 13(1), 19-27. DOI: 10.1080/19320248.2017.1393365

Ontario Home Economics Association. 2018. Food Literacy. https://www.ohea.on.ca/foodliteracy.html

Ontario Ministry of Education. (2019). The Ontario curriculum: Secondary social sciences and humanities. http://www.edu.gov.on.ca/eng/curriculum/secondary/ssciences.html

Peterborough Public Health. (2018). Food insecurity in Peterborough. https://www.peterboroughpublichealth.ca/wp-content/uploads/2018/03/2018-FoodInsecurity-Infographic.pdf

Reynolds, J., \& Hunter, B. (2017). Purchasing power; 10 lessons on getting more local, sustainable, and delicious food in schools, hospitals and campuses. Food Secure Canada. https://foodsecurecanada.org/purchasing-power-report

Ronto, R., Ball, L., Pendergrast, D., \& Harris, N. (2016). Adolescents' perspectives on food literacy and its impacts on their dietary behaviours. Appetite, 107, 549-557. DOI: 10.1016/j.appet.2016.09.006

Scrinis, G. (2008). On the ideology of nutritionism. Gastronomica, 8(1), 39-48. DOI: 10.1525/gfc.2008.8.1.39

Seligman, H. K., Laraia, B. A., \& Kushel, M. B. (2010). Food insecurity is associated with chronic disease among low-income NHANES participants. Journal of Nutrition, 140(2), 304-310. DOI: 10.3945/jn.109.112573

Slater, J. (2017). Food literacy: A critical tool in a complex foodscape. Journal of Family and Consumer Sciences, 109(2), 14-20. DOI: 10.14307/JFCS109.2.14

Slater, J. (2013). Is cooking dead? The state of Home Economics Food and Nutrition education in a Canadian province. International Journal of Consumer Studies, 37, 627-624. DOI: 10.1111/ijcs. 12042

Stahlbrand, L. (2016). The food for life catering mark: Implementing the sustainability transition in university food procurement. Agriculture, 6(46), 1-19. DOI: 10.3390/agriculture6030046

Sumner, J. (Ed). (2016). Learning, food and sustainability. Palgrave MacMillan. 
Sumner, J. (2013). Food literacy and adult education: Learning to read the world by eating. The Canadian Journal for the Study of Adult Education, 25(2), 79-92.

Tam, R., Yassa, B., Parker, H., O’Connor, H., \& Allman-Farinelli, M. (2016). University students' on-campus food purchasing behaviours, preferences, and opinions on food availability. Nutrition, 37, 7-13. DOI: 10.1016/j.nut.2016.07.007

Thomas, H., \& Irwin, J. (2011). Cook it up! A community-based cooking program for at-risk youth: An overview of a food literacy intervention. BMC Research Notes, 4, 495. DOI: 10.1186/1756-0500-4-495

Trent Central Student Association. (2014). A raw deal: A report on food services at Trent. https://issuu.com/trentcentral/docs/arawdeal

Truman, E., Lane, D., \& Elliott, C. (2017). Defining food literacy: A scoping review. Appetite, 116, 365-371. DOI: 10.1016/j.appet.2017.05.007

Valley, W., Wittman, H., Jordan, N., Ahmed, S., \& Galt, R. (2017). An emerging signature pedagogy for sustainable food systems education. Renewable Agriculture and Food Systems, 33(5), 467-480.

Velardo, S. (2015). The nuances of health literacy, nutrition literacy, and food literacy. Journal of Nutrition Education and Behaviour, 47(4), 385-389. DOI: 10.1016/j.jneb.2015.04.328

Worsley, A. (2015). From nutrients to food literacy. Journal of the Home Economics Institute of Australia, 22(3), 13-21.

Yamashita, L., \& Robinson, D. (2016). Making visible the people who feed us: Educating for critical food literacy through multicultural texts. Journal of Agriculture, Food Systems, and Community Development, 6(2), 269-281. DOI: 10.5304/jafscd.2016.062.011 